\title{
Bone Specific Alkaline Phosphatase Measurement
}

National Cancer Institute

\section{Source}

National Cancer Institute. Bone Specific Alkaline Phosphatase Measurement. NCI

Thesaurus. Code C92287.

The determination of the amount of bone specific alkaline phosphatase present in a sample. 